\title{
Pit latrines: A potential risk factor for latrodectism in rural South Africa?
}

\author{
A Msiwa, ${ }^{1} \mathrm{MB}$ ChB; S D Ntshalintshali, ${ }^{2} \mathrm{MB}$ ChB, MMed (Int Med), FCP (SA) \\ ${ }^{1}$ Department of Internal Medicine, Port Shepstone Hospital and School of Clinical Medicine, College of Health Sciences, University of KwaZulu- \\ Natal, Durban, South Africa \\ ${ }^{2}$ Division of Rheumatology, Tygerberg Hospital and Faculty of Medicine and Health Sciences, Stellenbosch University, Cape Town, South Africa
}

Corresponding author: S D Ntshalintshali (sipho.duncan@gmail.com)

Latrodectus spp. spider bites usually occur away from domestic sites, in the open fields or bushes. We report 3 cases of latrodectism that were identified to be associated with bites by these spiders in a rural domestic setting, specifically while the victim was using a pit latrine.

S Afr Med J 2019;109(11):848-849. https://doi.org/10.7196/SAMJ.2019.v109i11.14121

Risk factors for Latrodectus spp. spider bites described in the literature include occupations such as construction workers, agricultural workers, municipal and utility workers, domestic workers and entomologists. ${ }^{[1]}$ We report 3 cases of Latrodectus spider bites in the rural south-eastern part of South Africa (SA) that occurred while individuals were using pit latrines. One case was severe, requiring antivenom administration.

\section{Case reports}

Our index case was a 16-year-old scholar from rural Harding in KwaZulu-Natal Province, SA, with no previous comorbid conditions, who presented to St Andrew's Hospital in August 2018 with a history of sudden onset of confusion, muscle rigidity with pains, and diaphoresis a few hours after he had been bitten on the penis by a spider while using a pit latrine. On the same day he was given antitoxoid tetanus and transferred to Port Shepstone Hospital.

On arrival, the patient's vital signs were stable except for a slightly elevated systolic blood pressure of $142 / 82 \mathrm{mmHg}$. His pulse rate was $98 \mathrm{bpm}$, respiratory rate $18 / \mathrm{min}$, temperature $36.5^{\circ} \mathrm{C}$ and oxygen saturation $98 \%$ on room air. He was diaphoretic and restless and appeared to be in pain. The penile glans was swollen with clear bite marks. Neurological examination demonstrated delirium with no meningism, and he had generalised increased muscle tone. The rest of the systemic examination was unremarkable.

The results of dipstick urinalysis and a urine toxicology screen were completely normal, as were an electrocardiogram, arterial blood gas values and a chest radiograph. Additional blood tests were also normal except for a slightly elevated alkaline phosphatase level, as expected in a teenager (Table 1). The patient was given $10 \mathrm{~mL}$ of intravenous calcium gluconate $10 \%$, and $5 \mathrm{~mL}$ of intravenous Latrodectus antivenom to which he responded positively in a few hours, confirming the clinical suspicion of latrodectism. He was discharged with full recovery in 48 hours.

In rural Pondoland in Eastern Cape Province, $80 \mathrm{~km}$ south-west of Port Shepstone Hospital, 2 additional cases of mild latrodectism after using a pit latrine were reported at St Patrick's Hospital in Bizana in 2018 and early 2019, occurrences that have increased the suspicion of an association between pit latrines and latrodectism in rural SA. These patients did not require antivenom administration, and were discharged home on the same day after a few hours of observation.
Table 1. Blood results in the index case

\begin{tabular}{|c|c|c|}
\hline Investigation & Admission & Discharge \\
\hline WCC $\left(\times 10^{9} / \mathrm{L}\right)$ & 8.4 & 7.6 \\
\hline $\mathrm{Hb}(\mathrm{g} / \mathrm{dL})$ & 13.8 & 14.2 \\
\hline Platelets $\left(\times 10^{9} / \mathrm{L}\right)$ & 156 & 168 \\
\hline $\mathrm{T}$ bil $(\mu \mathrm{mol} / \mathrm{L})$ & 8 & 12 \\
\hline $\operatorname{ALT}(\mathrm{U} / \mathrm{L})$ & 23 & 29 \\
\hline $\operatorname{ALP}(\mathrm{U} / \mathrm{L})$ & 189 (normal 42 - 98) & 201 \\
\hline INR & 1.01 & 1.02 \\
\hline $\mathrm{Na}^{+}(\mathrm{mmol} / \mathrm{L})$ & 136 & 138 \\
\hline $\mathrm{K}^{+}(\mathrm{mmol} / \mathrm{L})$ & 4.5 & 4.2 \\
\hline $\mathrm{Cl}^{-}(\mathrm{mmol} / \mathrm{L})$ & 106 & 109 \\
\hline $\mathrm{C} \mathrm{Ca}^{2+}(\mathrm{mmol} / \mathrm{L})$ & 2.42 & 2.45 \\
\hline $\mathrm{Mg}^{2+}(\mathrm{mmol} / \mathrm{L})$ & 0.71 & 0.69 \\
\hline $\mathrm{PO}_{4}^{-}(\mathrm{mmol} / \mathrm{L})$ & 1.04 & 1.06 \\
\hline $\mathrm{HCO}_{3}^{-}(\mathrm{mmol} / \mathrm{L})$ & 22 & 22 \\
\hline Urea (mmol/L) & 6.7 & 5.2 \\
\hline Creatinine $(\mu \mathrm{mol} / \mathrm{L})$ & 52 & 61 \\
\hline
\end{tabular}

\section{Discussion}

Latrodectus refers to a species of neurotoxic spiders causing a clinical toxidrome called latrodectism that occurs following a bite. It results in various symptoms including diaphoresis, muscle rigidity, pain and flushing and may be associated with periorbital oedema. Latrodectism may present with varying degrees of severity resulting from mild, moderate and severe envenomation. ${ }^{[1]}$

There are 31 species of Latrodectus worldwide, with only 6 of these found in SA. These are L. cinctus (found in rural KwaZulu-Natal) and L. renivulvatus (found in the Eastern Cape), likely to have been the culprits in the cases described above (Figs 1 and 2), L. indistinctus, L. karooensis, L. rhodesiensis and L. geometricus. ${ }^{[1,2]}$

The spiders are typically $7-15 \mathrm{~mm}$ in length excluding the legs, and black in colour with red-orange stripes on the dorsal aspect of the spherical abdomen. As the spider ages, the red markings decrease with each moult until an adult spider may be left with a single red spot above the spinnerets. ${ }^{[3]}$ 


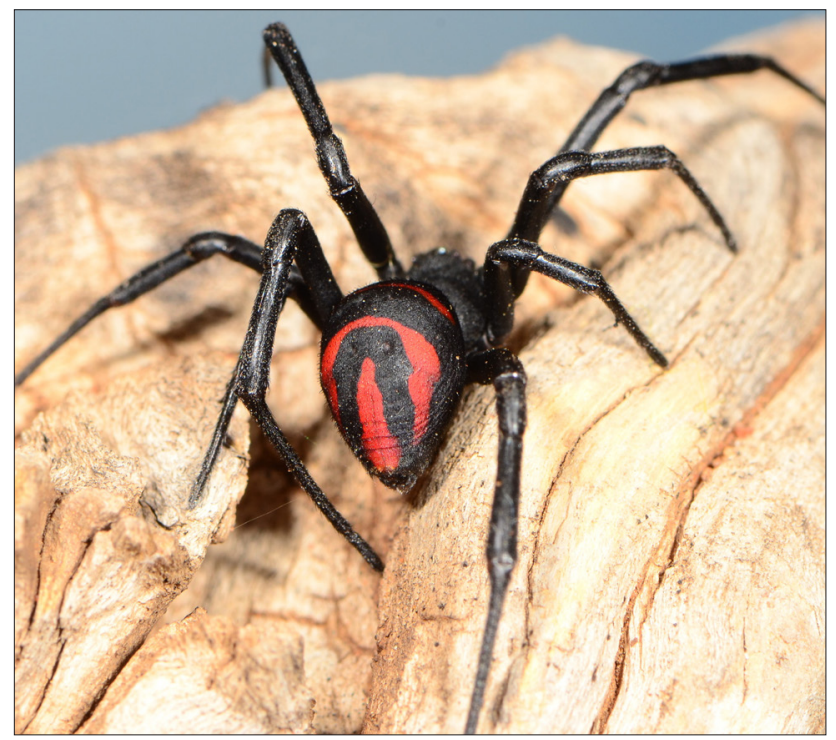

Fig. 1. Latrodectus cinctus (photo by Peter Webb).

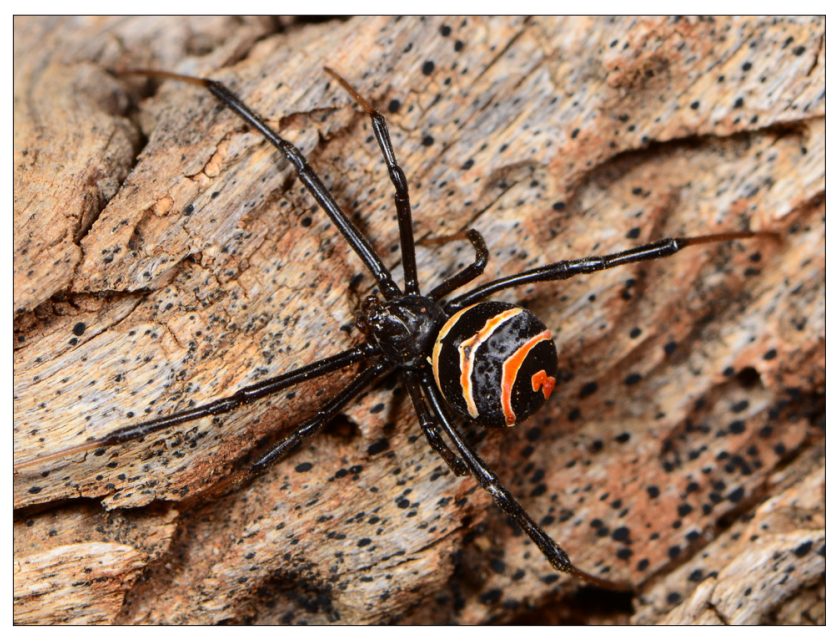

Fig. 2. Latrodectus renivulvatus (photo by Peter Webb).

Bites by Latrodectus spiders are rarely fatal, although in a sufficiently large amount the venom may overwhelm a child or an already compromised adult, resulting in a fatal outcome. The neurotoxin released by the spider causes increased release of neurotransmitters, acetylcholine and noradrenaline, resulting in the typical systemic manifestations. ${ }^{[3]}$

Latrodectus is normally categorised as a veld species (i.e. living in open, uncultivated country or grassland), and bites in a domestic setting are usually attributed to translocation of the spider. Only the female spiders can bite humans, as their fangs are large enough to penetrate the skin. People at most risk include construction workers in rural sites, agricultural workers and workers in the veld. ${ }^{[1,3]}$
Mild cases of latrodectism usually only require close monitoring, while more severe cases may require administration of calcium gluconate and of the antivenom, an equine immunoglobulin obtained from horses immunised with Latrodectus spp. venom. It neutralises the venom at the presynaptic membrane, thereby decreasing neurotransmitter release and consequently inhibiting the effects of the venom. There may be an allergic reaction after antivenom administration, but only one fatal case (in an asthmatic patient) has been reported. ${ }^{[2]}$

According to the SA national census of $2011,{ }^{[4]} \sim 57 \%$ of the population used flush toilets ( 30 million people), $31 \%$ pit toilets (16 million people), $3 \%$ chemical toilets (1.5 million people) and $2 \%$ bucket toilets ( 1 million people), with $7 \%$ (4 million people) unaccounted for. The dark, moist, filthy and insect-rich environment of pit toilets resembles that of caves in many respects, and serves as an ideal habitat for spiders in general. ${ }^{[5]}$ The theory that pit latrines in rural SA could be a potential risk factor for latrodectism is plausible.

\section{Learning points}

Pit latrines have not been associated with latrodectism in the literature. The cases reported suggest a potential risk factor relationship between latrodectism and pit latrines in rural SA.

The significant number of pit latrine users in South Africa (31\% according to the 2011 census) highlights the need to educate users about the potential risk of spider bites.

Rural municipal authorities across the country should be informed about the need to prioritise the eradication of pit latrines, as they pose a potential health hazard for the users. Interim use of municipal monitored mobile toilets could be considered while awaiting construction of flush toilets, the ideal.

\section{Declaration. None.}

Acknowledgements. Special thanks to Dr B N Ntshalintshali for the information on the two patients from St Patrick's Hospital.

Author contributions. AM: literature review, manuscript draft; SDN: identification of the case for publication, draft, revision and approval of manuscript for publication.

Funding. None.

Conflicts of interest. None.

\footnotetext{
Snyman C, Larsen N. Spider bite and its treatment in southern Africa. Occup Health South Afr 2005;March/April:22-26

2. Muller GJ. Black and brown widow spider bites in South Africa. S Afr Med J 1993;83:399-405.

3. Thomas TS, Kemp A, Roberg KP. Black widow spider bite in Johannesburg. South Afr J Infect Dis 2018;33(3): 86-88. https://doi.org/10.1080/23120053.2018.1453271

4. Statistics South Africa, Census 2011. Statistical release (revised) P0301.4. Pretoria: Stats SA, 2012:5965 .

5. Mammola S, Isaia M. Spiders in caves. Proc Biol Sci 2017;284(1853):1-10. https://doi.org/10.1098/ rspb.2017.0193
}

Accepted 29 July 2019 